\title{
Research on the Status Quo and Development of Engineering Management Discipline in China
}

\author{
Yuhai Miao \\ City Institute, Dalian University of Technology, Dalian, Liaoning Province, P.R. China, 116600
}

Keywords: status quo; development; engineering management discipline; China

\begin{abstract}
With the rapid development of the social economy, the demand for engineering management talents in economic construction has also increased. However, there is still room for improvement in the training of talents in engineering management disciplines. This paper analyzes the current situation of engineering management subject teaching in China, explores the problems exposed in teaching, and puts forward effective measures to promote the development of disciplines.
\end{abstract}

\section{Introduction}

With the development of science and technology, all walks of life have begun to combine with the latest scientific and technological means, and innovate in various industries to obtain more benefits. As one of the major industries of urban development in China, construction engineering also requires more and more professional engineering management personnel with excellent professional qualities to participate in the overall planning, planning and management of construction projects. However, although professional disciplines related to engineering management are being established in more and more colleges and universities, they are limited by many factors such as the strength of teachers and hardware facilities, and the professional talents of engineering management are far from meeting the current construction in terms of quantity and quality [1].

\section{Development Status of China's Engineering Management Subjects}

At present, the division of engineering management disciplines in Chinese universities generally falls into the following categories. The first case is to divide engineering management disciplines into management or economic disciplines. For example, Xi'an Jiaotong University will assign project management to management colleges; the second is to divide engineering management disciplines into architectural or civil engineering disciplines. For example, Tsinghua University assigns engineering management majors to the School of Civil and Hydraulic Engineering for teaching; the third is to separate engineering management disciplines into a single college for teaching, such as the investment of Chongqing University's construction management and central university of finance and economics. The above three types of divisions are the more common three situations. In the actual teaching process, colleges and universities set up disciplines according to the objectives of their respective professional training programs.

As a discipline that is closely related to practical work, engineering management is open to a large number of postgraduate, undergraduate, specialist and on-the-job training schools. Taking colleges and universities as an example, the engineering management majors are open in comprehensive, agricultural and forestry, financial, teacher, and science and engineering universities. Among them, the three types of universities, namely, engineering, finance, and teacher, are the main schools. At each level, the goal is to train engineering management talents at different levels, and to train engineering management professionals for the society [2].

Due to the different disciplines, the training system for international engineering management talents is different. A professional requirement is that, after systematic study, professional talents in engineering management should have professional basic knowledge in the field of architecture. 
They should cultivate professional awareness and certain leadership and overall planning capabilities in order to better serve the construction engineering management industry; another professional orientation It is required to cultivate learners' comprehensive management capabilities and management expertise in order to cultivate comprehensive talents.

China has integrated the positioning requirements of the above two disciplines. The education department stipulates that talents in engineering management should learn professional knowledge in management, economics, and engineering technology, and have a strong comprehensive ability to solve the economic problems arising in construction projects and related professional issues in the field of architectural engineering: The basic theory of engineering management (including real estate) management, mastering professional knowledge of construction and related policies and regulations, familiar with the status quo and dynamics of engineering management development at home and abroad, capable of proficiently using computers to solve professional problems, and having basic data information searching and summarizing capabilities such as document retrieval. Master knowledge of economics and have certain foreign language skills.

With the development of society and economy, the technical quality of engineering construction projects has continuously increased, and the demand for professional engineering management personnel has also increased. At present, some universities in China have already opened related disciplines in engineering management, and with the expansion of enrollment in colleges and universities, and the tendency of candidates to combine professional work with practical work, engineering management is not an unpopular profession in various universities, and the number of applicants is relatively large. And after graduation, it can reach an employment rate of more than $85 \%$ [3].

However, due to the differences in the professional placement, faculty strength, and hardware facilities of different colleges and universities, there are differences in the types of courses and the quality of education accepted by engineering management personnel graduated from different colleges during the undergraduate period. This difference is from professional quality and employment. It can be reflected in the situation. According to relevant surveys, the professional qualities and employment status of graduates from key universities in China are significantly better than those of ordinary university graduates, but graduates with predominance majors in engineering management can clearly find better jobs in colleges at the same level. From the perspective of colleges and universities, the development of engineering management disciplines at different levels and different strengths is also obviously different.

\section{The Development of Engineering Management Professional Education}

The education of China's engineering management profession has achieved great results through the efforts of the Teaching Guidance Committee of the Engineering Management Department of the Ministry of Construction and various institutions; the education management educators of both the Steering Committee and the various institutions have made it clear that the training objectives of the project management profession are Basic knowledge of engineering technology, management science, and economics. However, from the results of the survey, there are still some problems in the existing professional education in engineering management: the talent training in engineering management education must be oriented to the practical and social needs of the project. This is an urgent need for China's future economic development. It also includes foreign engineering management education. With the experience of industrial development, the talents (especially undergraduates) trained in the existing engineering management professional education lack the ability to solve practical problems. It takes a long time for the graduates to go to the company to adapt to the needs of the actual work. Based on the results of the research and the results of comprehensive research, the author believes that China's engineering management education can improve the quality of education from the following aspects.

As mentioned above, there are two different views on the cultivation of engineering management professionals in foreign countries. One is construction management, that is, management of the construction industry, and the other is For engineering management, that is, management based on 
engineering and technological activities; there are two aspects that have the same aspect, that is, emphasis on the dependence of engineering management on engineering technology, but the specific dependence on technology and industry background is different, the former emphasizes the construction industry, because no matter what Project investment in the industry needs to involve construction engineering or civil engineering activities more or less, so it is reasonable to emphasize engineering technology that depends on the construction industry. Considering the history and reality of China's engineering management school, give full play to the advantages of various institutions, accurately and reasonably position each school's engineering management professional education, and take advantage of the school to develop professional characteristics in order to better serve the society and meet the needs of the society. The advantages of various institutions are mainly reflected in the engineering technology or school-running characteristics they rely on. In order for the engineering management professional to better meet actual needs, it is necessary to increase the specific engineering and technical capabilities of the service industry on the basis of common engineering and technical capabilities. From the results of the survey, students with obvious industry backgrounds will be employed. The proportion of the school's industry is relatively high. For example, graduates of engineering management from Southwest Jiaotong University go to the Ministry of Railways as much as 50\% of the total number of units. Therefore, it is necessary to increase the training of engineering technology in specific industries; Akron University's engineering management program Its engineering technology platform courses can be selected from the fields of bioengineering, electric power engineering, mechanical engineering, chemical engineering, and computer engineering. For financial institutions, their ability to cultivate engineering skills is lacking, but they can give full play to their economic and management education advantages [4].

The existing training system for engineering management undergraduate education in China basically follows the curriculum system set by the Engineering Management Education Steering Committee. Based on the results of the survey, it is necessary to further improve and optimize the knowledge management system of the engineering management discipline according to the knowledge progress and development trend of the discipline, learning from the experience of running a foreign country, and taking advantage of the needs of the colleges and universities. Judging from the overseas experience in engineering management, the undergraduate knowledge system emphasizes the integration of engineering technology and management theories and methods based on engineering technology activities. In the graduate student stage, a significant portion of the training target comes from the engineering community. Training focuses on management and economic theories and methods. For example, Brunel University's graduate programs in engineering management mainly include: human resources and organizational management, financial management, marketing, project management, production and operations management, quality management, information systems, manufacturing strategies, etc. . The cultivation of postgraduates in engineering management in China (such as MBAs with specialties and masters in engineering projects) basically follow this principle. The focus of the knowledge system on the adjustment and optimization of engineering management disciplines for engineering colleges is to strengthen the industrial background engineering technology. For example, according to the characteristics of the school, the engineering technology basic courses in the school's industry can be strengthened. From the results of the survey, at present, there are several distinct industry backgrounds in China's engineering colleges for engineering management: civil engineering, transportation, resource extraction and processing, aerospace, and manufacturing. (There are some agricultural and forestry universities in China. The engineering management major is also established, and the background of agriculture and forestry relied on is also very obvious.) For the above-mentioned institutions with special characteristics, the basic engineering technology courses for the industries in which they are based, such as the mining industry, can be appropriately increased on the basis of civil engineering techniques. Can increase mining, mineral processing, material processing courses. For financial institutions, because of their lack of training ability in engineering technology, it is critical to strengthen the education and ability training of management 
science and economics. Of course, it is necessary to master certain engineering technology basic knowledge [5].

One of the important means to improve the ability of engineering management professionals to solve practical problems is to increase the practical teaching of engineering management. To achieve this goal, project management education must be closely integrated and cooperated with the enterprise. On the one hand, students should move toward the enterprise and practice training should be added during the learning process. On the other hand, experts who have long been engaged in engineering management can be hired to work in schools. Practice platform construction is the foundation for enhancing the practice of strengthening engineering management professionals. It is necessary to mobilize input from various sectors, improve the experimental and practical conditions, and promote the importance of practical teaching and practical training for all school-based units: in accordance with the requirements of the "Laboratory Work Procedures for Colleges and Universities", Further strengthen the standardization and institutionalization of laboratory construction and management, guide higher schools to increase investment in laboratory construction, improve the level of laboratory construction and the level of management and utilization; carry out internships and practice training bases for corporate college students Selection, construction and listing work. In some enterprises with better conditions, we should establish extra-curricular internships and practical training bases for college students, and take students' training outside schools as the basis to further promote the integration of production, learning and research, so as to play a mutually beneficial role.

\section{Conclusion}

Engineering management, as a discipline with high level requirements for talents under the rapid development of science and technology, plays a role that cannot be overlooked in the actual work of engineering construction. As the main way to train high-quality talents, college education is the main way to train engineering management talents. In the actual teaching process, there are still development problems such as unfair quality of talents and differences in employment due to imperfect system norms. By formulating a unified professional knowledge system and perfecting continuing education and other measures, I believe that the discipline of engineering management will radiate new vitality and vitality in various universities and colleges, and cultivate more highly qualified engineering management professionals for the society.

\section{References}

[1] Yue Yafeng. Current situation and development trend of China's engineering project management model [J]. Shanxi Architecture, 2009, 15: 180-181.

[2] Lu Yang. Analysis of project project management status and scientific development strategies [J]. Manager, 2009, 13:204.

[3] Cao Mingjiang. Discussion on the current situation and development trend of China's engineering project management [J]. Sichuan Architecture, 2009, 05:228-229+231.

[4] Yin Yulin, Liu Yige. Exploration and research on the appraisal of professional undergraduates' application abilities - Taking the engineering management specialty as an example [J]. Modern Educational Technology, 2013, 11:119-123+89.

[5] Liu Chunjiang, Zhou Tianhua, Zhang Jingxiao. Research on Talent Cultivation Model of Engineering Management Professional Based on P-CMM [J]. Journal of Engineering Management, 2014, 02:153-158. 